\title{
Social Networks, Interpersonal Social Support, and Health Outcomes: A Health Communication Perspective
}

\author{
Kevin Wright* \\ Communication, George Mason University, Fairfax, VA, USA
}

This manuscript discusses the development, impact, and several major research findings of studies in the area of social network support and health outcomes. The review focuses largely on the development of online social support networks and the ways in which they may interact with face-to-face support networks to influence physical and psychological health outcomes. The manuscript discusses this area, and it presents a research agenda for future work in this area from an Associate Editor's perspective.

Keywords: social support, health outcomes research, social networks, communication processes, online communication

OPEN ACCESS

Edited by:

Shaunak Sastry,

University of Cincinnati, USA

Reviewed by:

James Olumide Olufowote,

University of Oklahoma, USA

Pamara Chang,

University of Cincinnati, USA

${ }^{*}$ Correspondence:

Kevin Wright

kwrigh16@gmu.edu

Specialty section:

This article was submitted

to Health Communication,

a section of the journal

Frontiers in Communication

Received: 19 August 2016 Accepted: 29 September 2016 Published: 14 October 2016

Citation:

Wright K (2016) Social Networks, Interpersonal Social Support, and Health Outcomes: A Health Communication Perspective.

Front. Commun. 1:10. doi: 10.3389/fcomm.2016.00010
Decades of research studies have found that our social networks and interpersonal relationships have a substantial impact on our physical health and our psychological well-being (Burleson et al., 1994; Cohen et al., 2000; Shaw and Gant, 2002; Goldsmith, 2004; Goldsmith and Albrecht, 2011; Thoits, 2011). Controlling for known determinants of morbidity and mortality, a number of studies have shown that people with low social support levels have a higher risk of mortality compared to people who have stronger and more satisfying support networks (Berkman and Syme, 1979; Cohen et al., 2000). In addition to being positively correlated with health, positive types of social network support can reinforce health behavior change, while negative types of social network influence can undermine health behavior change (Revenson et al., 1991; Amick and Ockene, 1994; Goldsmith, 2004). For example, having a large number of peers who smoke cigarettes may negatively affect the success rate of a patient's quitting attempts. Moreover, people may give a person who is struggling with a health issue false, misguided, or incomplete support (Helgeson and Gottlieb, 2000).

This area of research has also uncovered a surprising complex array of social, relational, psychological, and environmental variables that make it challenging to study the specific mechanisms of how social network members impact our health in good and bad ways (Goldsmith and Albrecht, 2011). Research indicates that negative aspects of social networks and relationships can lead to negative health outcomes. For example, relational conflict, role obligations, and unwanted or insensitive advice from a friend can increase stress levels and lead to negative health outcomes (Goldsmith and Albrecht, 2011). Other problems related to social networks and social support can occur due to a variety of differing perceptions, cultural influences, and other environmental factors. Social network members may avoid communicating with a person or fail to provide satisfying support when it is needed most. Research has found that this often happens when an individual is seeking support for a stigmatized health condition (Wolitski et al., 2008; Wright and Miller, 2010; Wright and Rains, 2013). For example, cancer and HIV sometimes frighten people into silence or avoidance. Moreover, inadequate support from friends may occur if they feel that you have brought on your own health problems through unhealthy lifestyle decision, such as over-eating, smoking, or drinking alcohol (Goldsmith, 2004). Our social support networks are dynamic and often change dramatically 
throughout the life span, or due to positive and negative stressful life events, such as the birth of a child or being diagnosed with a life-threatening illness (Burleson et al., 1994). At the same time, stressors in life are also dynamic in nature. For example, changes in new communication technologies over the last two decades have created an environment where it can be difficult to disengage from 24/7 workplace issues (Wright et al., 2014) or the never-ending world of social media and text exchanges among our online social network members (Hall and Baym, 2012). In this sense, interpersonal relationships are both beneficial to our health and can also serve as sources of stress.

Research findings suggest that a shift toward using online networks for social support more frequently (paralleling the growth of the Internet and social media use) has occurred in recent years. This has led to the rise of online support groups/ communities for people facing health concerns, expanding from several thousand support groups/communities in the late 1990s to hundreds of thousands of groups/communities by 2012 (Wright and Bell, 2003; Chou et al., 2009; National Cancer Institute, 2013). Many of these communities consist of peers who are experiencing common health concerns, while other online health-related support communities include opportunities to interact physicians or other health-care providers (e.g., such as WebMD). Studies have found that these groups/communities can offer a number of advantages (and some disadvantages) in terms of social support. For example, compared to face-to-face support networks, online health support groups/communities are frequently used by individuals with rare health conditions/issues that are not well understood by physicians, conditions/issues that are difficult for healthcare providers to explain in layperson terms, or if members of one's primary social network (i.e., friends and family members) have limited knowledge of their health condition (Tanis, 2008; Campbell-Grossman et al., 2009; Tong et al., 2013). Moreover, online support groups provide convenient connection with others in similar circumstances, ability to communicate anonymously, reciprocity of social support, and a judgmentfree space for people to share information about their health status (Hwang et al., 2010; Wright, 2015). However, researchers have also identified potential negative aspects of online support communities, including flaming and delayed feedback, shortterm participation, negative social comparisons, and credibility issues surrounding the sharing of health information (Wright, 2000b; Wright and Bell, 2003). Due to these issues, many individuals feel that they receive inadequate informational support from their traditional social networks and health-care providers; and they may perceive online support groups/communities as a better alternative for receiving health information (Wicks et al., 2010).

Furthermore, research on online support communities for people who are living with health problems has found that online community members are capable of drawing upon the collective experience of participants who share a health issue in ways that are not possible in the face-to-face world since the Internet allows people to access and interact with others in the community across geographical boundaries (Wright, 2015). Online sources of social support appear to replace or extend traditional offline support networks in terms of providing greater access to the increased social capital available in a larger, easier to maintain network of individuals who are often geographically separated (Walther and Boyd, 2002; Ellison et al., 2007; Kim and Lee, 2011). The Internet can help individuals facing health concerns during times of stress and transition to access new networks of support, such as connections with others facing the same or similar transitions and stressors (such as if a person moves to a small town where the likelihood of meeting others living with a similar health condition is low). In addition to convenience, online sources of social support can also help people with health problems overcome accessibility barriers and high service fees associated with other (more traditional) sources of information and support, such as therapy (Barrera, 2000). The asynchronous and mediated nature of online communication helps alleviate time and space barriers that exist for support settings that require the simultaneous presence of conversational partners (Turner et al., 2001). These online support sources or communities can often offer people who are coping with health problems higher quality health information and support for health behavior change than is available among traditional, face-to-face sources of support.

In recent years, smartphones have become the primary way people gain access to the Internet and social media. New mobile applications have taken advantage of the media convergence potential of smartphone (e.g., GPS combined with wireless Internet, video, etc.). At the same time, we have witnessed the emergence of wearable electronic devices that track physical activity (e.g., Fitbit). Both innovations have led to the burgeoning field of MHealth (Luxton et al., 2011; Boulos et al., 2014). While much of this research has examined the impact of smartphones on provider-patient communication, a number of researchers have examined the social support potential of smartphones (Boulos et al., 2014). Although diet and exercise applications and devices are currently the most widely used health-related features of smartphones (Boulos et al., 2014), other applications are available for a variety of health issues, including alcohol addiction recovery support, smoking cessation support, and support for mental health issues (Luxton et al., 2011; Alvarez-Jimenez et al., 2014; Boulos et al., 2014). These types of MHealth applications can allow researchers to access available data from smartphones, including activity levels and diet information, which can be used as important health outcome measures. Moreover, these applications also provide the names/ online contacts of online social network members with whom an individual shares his or her health information via these applications. This allows research to examine the structure of online support networks through methods such as online social network analysis. Of course, getting permission to access all of these potential sources of data come with a host of challenges in terms of respecting the privacy/confidentiality of research participants as well as increased scrutiny by institutional review boards across universities.

Interest in the links between social networks and health outcomes is certainly not limited to social support researchers, new media scholars, and interpersonal health communication scholars. Health campaign researchers have become increasingly 
aware of the need to integrate social networks and interpersonal relationships into population-based health-care interventions (Valente and Saba, 1998; Beaudoin et al., 2006; Abroms and Maibach, 2008; Chou et al., 2009; Chee et al., 2016). These social relationships are often important in terms of helping target audience members change and maintain healthy behaviors, such as diet and exercise and getting screened for colon cancer. Even "low tech" features of smartphones, including text messaging, have been used in health interventions, particularly in the developing countries (Déglise et al., 2012; Head et al., 2013). These types of interventions also provide opportunities for researchers to better understand how texting and other older technologies can be used for social support and improvement of health outcomes among people in developing countries.

In short, the relationship between support from our social network members and our health is complex. Social networks and the specific interpersonal relationships within them permeate every aspect of most people's lives, and their role in influencing positive health outcomes will likely continue to be an important area of study for years to come.

\section{MY RESEARCH BACKGROUND IN SOCIAL SUPPORT AND HEALTH OUTCOMES}

As a scholar who has been studying social support, communication processes, and health outcomes for nearly 20 years, I have had the pleasure of following many streams of exciting research in the multidisciplinary study of social support and health outcomes. The evolution of new communication technologies during this time period has dramatically influenced the ways in which we communicate with our friends, families, and other social network members (e.g., coworkers, distant friends, and weak ties we encounter in online settings). Beginning in the mid-1990s, online support groups and communities began to develop on the Internet focusing on providing support for people who are coping with a wide variety of health conditions as well as communities for caregivers for loved ones experiencing health issues. A number of researchers began to take notice of these groups, and this was the beginning of many descriptive research studies (Braithwaite et al., 1999; Finn, 1999; Turner et al., 2001), including some of my own (Wright, 2000a,b).

From the late 1990 s through the 2000 s, I served as an editorial member and frequent review for the journals Health Communication and the Journal of Health Communication, and as the editor for the Journal of Computer-Mediated Communication. These service roles allowed me to watch the development of interesting research findings and theory development in the areas of social support, communication, and health, as well as computermediated communication. As time went on, scholars began to merge theory from both areas in an attempt to make stronger causal claims about the influence of social support network members on specific health outcomes (Han et al., 2012; Liu and Yu, 2013; Oh et al., 2014), by advancing and testing hypotheses stemming from these theoretical frameworks. Numerous extraneous variables and mediating variables have been identified, and they are now being controlled for in much of today's online social networks and health outcomes research.

\section{A RESEARCH AGENDA FOR THE STUDY OF SOCIAL NETWORK SUPPORT AND HEALTH OUTCOMES}

My hope is that more scholars from a variety of perspectives and contexts will consider examining the influence of social network support (both face-to-face and online) on health outcomes. For example, researchers who are interested in health communication issues from intrapersonal, interpersonal, small group, organizational, mass communication, and health campaigns research backgrounds can all benefit from including social support networks variables into their research studies. The findings from the literature in this area support for the idea that both faceto-face and online support networks appear to benefit people who are struggling with health problems and in terms of maintaining long-term health behavioral changes. Some individuals prefer support from close, face-to-face relational partners, while others are drawn to online support due to the advantages it may offer. For example, as we have seen, people who are coping with stigmatized health issues or individuals who lack traditional support resources in the face-to-face world may find online support networks (in the form of an online support community) to be more beneficial than face-to-face support networks.

Theories and methods in future research need to take into account a more comprehensive perspective of the influence of both types of social support on health outcomes, including the main effects and interaction effects of online and offline sources of social support, additional predictors of engaging in online support, mediated variables (i.e., the influence of different computer-mediated channels and contexts), and key demographic and environmental variables on health outcomes. Research is also needed to examine interaction(s) between faceto-face and online social support networks as well as how new communication technologies are facilitating the intersection of virtual and face-to-face interactions through media convergence (e.g., GPS chips and applications that allow you to find key people in your support network in the face-to-face world). For example, although research has examined the influence of mobile games on physical activity levels (Dunton et al., 2011; Fanning et al., 2012), few of these studies have specifically focused on the role of social support on health outcomes within this context. More research is needed to better understand a wider variety of health issues and the influence of multimodal communication (e.g., online communication combined with face-to-face interaction) and mobile/ online social support processes on key health outcomes, such as stress, depression, and physical health.

Future studies are needed that draw upon big data regarding online social support networks and health. The majority of research studies to date have relied on relatively small nonprobability samples and self-report measures (van Ingen and Wright, 2016). However, with the development of computer programs that measure various Internet usage patterns, such as social network analysis programs and other online analytics, large amounts of data regarding the structure and composition of a person's online social support network and the types of web information and sources he or she downloads can be integrated into study designs (along with self-report measures) that may 
help scholars gain a better understanding of the complexity of online social support network influence on health outcomes.

As research studies on social support networks/relationships and health continue to develop, more meta-analyses and metaanalytic reviews will be needed to assess the impact of social networks/relationships on health across similar studies. Metaanalytic reviews have contributed greatly to our understanding of newer areas, such as online support group network, influences on health. For example, Rains and Young (2009) conducted a meta-analysis of 28 published online support group studies dealing with people coping with health concerns and found that greater participation in their online support groups was related to increased perceived support, reduced depression, increased quality of life, and increased self-efficacy in terms of managing health problems. Meta-analytic can also help researchers identify key mechanisms that help to explain or moderate the influence of online support networks on health outcomes. For example, such studies [e.g., Rains et al. (2015)] have identified differences in online support perceptions and health outcomes based on the degree of health-related stigma people experience and characteristics of the health issue they face (e.g., controllability, duration, impact on relationships, etc.). Future work in this area would benefit from examining differences between how online support is conveyed in different online modalities and how this, in turn, influences health outcomes.

More studies are needed to better understand complex cultural differences in how social support networks influence is conceptualized, how social support communication processes may differ, and cultural influences on health outcomes across a wide variety of cultural contexts. In addition, more research is needed in the area of cross-cultural and international comparisons in terms assessing the relationship between social network and interpersonal dyadic support on important health outcomes (including regionally specific health issues) (Goldsmith and Albrecht, 2011). In addition, more research is need to better understand how online social support is used by older adults and the challenges they may face in terms of accessing and using newer communication technologies. While researchers have examined online support and health-related technology for older adults (Wright, 2000a; LeRouge et al., 2014), more research and interventions are needed to design online support platforms and technologies for older adult populations. Qualitative research and quantitative studies can both make important contributions to the study of cultural influences on social support network and health outcome processes (as well as to the larger area of social support and health research). While quite a bit research in the area of social network support and health outcomes has been conducted in a variety of countries around the world, most of the research has been conducted in a relatively small number of countries in Europe and Asia (mainly China) (Van Tilburg, 1998; Sun et al., 2007; Deng et al., 2010; Rao et al., 2012).

Newer studies have started to investigate social support and health in many other regions of the world (Kanbara et al., 2008; Ncama et al., 2008; Sivaram et al., 2009). However, large-scale meta-analysis studies and attempts to compare findings from different regions of the world are needed, and this presents social support and health researchers with an opportunity to help us to better understand the similarities and differences in social network support processes and health outcomes from different international and cultural perspectives.

While scholars have identified a number of theoretical frameworks that help to explain key advantages and disadvantages of both face-to-face and online support networks and their relationship to health outcomes (Wright, 2015), new theoretical perspectives are needed to capture the complexity of this phenomenon. Some prominent theories that have been used in previous work as a framework for understanding online social support processes and outcomes include social comparison theory, the buffering/ direct effects models of social support, the optimal matching model, weak tie support network theory, and social information processing theory [see review by Wright (2015)]. However, many of these theories were developed either in the face-to-face world or they were not developed with online social support processes in mind. Scholars should work on integrating overlapping concepts from major theories of face-to-face social support, online social support, and computer-mediated communication theory. For example, there is evidence that support from online social networks may interact with face-to-face support networks in interesting way to influence health outcomes (Nabi et al., 2013). Even "low tech" features of smartphones, including text messaging, have been used in health interventions (including interventions that are social support based), particularly in developing countries (Déglise et al., 2012; Head et al., 2013).

Although more recent studies have moved toward experimental designs and intervention approaches in an effort to better predict health outcomes for individuals who participate in such groups/communities, more research is needed to gain a better understanding of intervening variables that may influence the relationship between face-to-face and online network support and various health outcomes, using longitudinal designs and that target the health needs of more diverse populations. There is also a need for more interdisciplinary and translational research in this area. Certainly, there are many important stakeholders who are interested or affected by the emergence of research findings on online support and health outcomes, including researchers from multiple disciplines (I am aware of several disciplines where research is being conducted in this area, including communication, health informatics, instructional technology, medicine, nursing, psychology, and sociology). Moreover, there are many other stakeholders, including health-care providers, hospital administrators, patients, patient advocacy groups, and government health-care agencies.

Unfortunately, many academic researchers read research that has been published with their own discipline; however, future researchers should consider forming interdisciplinary research teams with scholars from other disciplines who have expertise in this area. Over the past few years, I have begun to collaborate with scholars in sociology in the Netherlands and medical researchers in Denmark in attempt to bring aboard fresh perspectives on the relationship between online social support and health as well as the opportunity to conduct cross-cultural comparisons between similar data sets. Interdisciplinary research is challenging due to the educational and cultural differences between participants, but it can also lead to stronger study designs and exposure to 
different theoretical explanations for study findings. Finding ways to effectively communicate research findings in this area in a way that will resonate with various stakeholders is an important goal of translational scholarship. Researchers need to find ways to better convey their research findings to multiple audiences so that the reach of this body of research can be expanded to a wider number of stakeholder groups. Establishing ongoing relationships with various stakeholders can help researchers learn more about the interests and needs of these stakeholders, which may spur research ideas and help researchers to translate their research findings more effectively.

\section{CONCLUDING THOUGHTS}

With the launch of Frontiers: Health Communication, I welcome manuscripts that address social network support and health issues in diverse ways. Literature reviews, meta-analyses, databased studies, and theoretical pieces can all contribute to our understanding of social network support processes and their effects on health outcomes across a wide range of cultural contexts. Certainly, qualitative, quantitative, content analyses, and other methodological approaches to understanding these issues are welcome. Of course, research that deals with other aspects of

\section{REFERENCES}

Abroms, L. C., and Maibach, E. W. (2008). The effectiveness of mass communication to change public behavior. Annu. Rev. Public Health 29, 219-234. doi:10.1146/ annurev.publhealth.29.020907.090824

Alvarez-Jimenez, M., Alcazar-Corcoles, M. A., Gonzalez-Blanch, C., Bendall, S., McGorry, P. D., and Gleeson, J. F. (2014). Online, social media and mobile technologies for psychosis treatment: a systematic review on novel user-led interventions. Schizophr. Res. 156, 96-106. doi:10.1016/j.schres.2014.03.021

Amick, T. L., and Ockene, J. K. (1994). "The role of social support in the modification of risk factors for cardiovascular disease," in Social Support and Cardiovascular Disease, eds S. A.Shumaker and S. M.Czajkowski (New York: Plenum Press), 259-278.

Barrera, M. (2000). "Social support research in community psychology" in Handbook of Community Psychology, eds J.Rappaport and E.Seidman (New York: Kluwer Academic/Plenum), 215-245.

Beaudoin, C. E., Thorson, E., and Hong, T. (2006). Promoting youth health by social empowerment: a media campaign targeting social capital. Health Commun. 19, 175-182. doi:10.1207/s15327027hc1902_9

Berkman, L. F., and Syme, S. L. (1979). Social networks, host resistance, and mortality: a nine-year follow-up study of Alameda County residents. Am. J. Epidemiol. 109, 186-204.

Boulos, M. N. K., Brewer, A. C., Karimkhani, C., Buller, D. B., and Dellavalle, R. P. (2014). Mobile medical and health apps: state of the art, concerns, regulatory control and certification. Online J. Public Health Inform. 5, e229. doi:10.5210/ ojphi.v5i3.4814

Braithwaite, D. O., Waldron, V. R., and Finn, J. (1999). Communication of social support in computer-mediated groups for people with disabilities. Health Commun. 11, 123-151. doi:10.1207/s15327027hc1102_2

Burleson, B. R., Albrecht, T. L., and Sarason, I. G. (1994). Communication of Social Support: Messages, Interactions, Relationships, and Community. Newbury Park, CA: SAGE.

Campbell-Grossman, C. K., Hudson, D. B., Keating-Lefler, R., and Heusinkvelt, S. (2009). New mothers network: the provision of social support to single, low-income, African-American mothers via email messages. J. Fam. Nurs. 15, 220-236. doi:10.1177/1074840708323048

Chee, W., Lee, Y., Im, E. O., Chee, E., Tsai, H. M., Nishigaki, M., et al. (2016). A culturally tailored Internet cancer support group for Asian American breast health communication is welcome as well. I hope that this article provides some background on one of my main areas of health communication research over the past 20 years, although I have also published research in the areas of medical tourism, providerpatient communication, and health campaigns. The idea that our social networks and interpersonal relationships have a crucial influence on our health is what initially drew me to the study of health communication. After nearly 20 years of researching this area, I have many more questions about this phenomenon than when I was a young scholar. With the rise of online social media and other newer communication platforms, we have seen a tremendous amount of research on the many ways social network support via computer-mediated channels may influence health outcomes. I am excited to see where social network support and health outcomes research will go in the next decade, and I hope that many articles in this journal will contribute to scholarly conversations about this phenomenon as well as cutting-edge research that extends our understanding of it.

\section{AUTHOR CONTRIBUTIONS}

The author confirms being the sole contributor of this work and approved it for publication.

cancer survivors: a randomized controlled pilot intervention study. J. Telemed. Telecare. doi:10.1177/1357633X16658369

Chou, W. Y. S., Hunt, Y. M., Beckjord, E. B., Moser, R. P., and Hesse, B. W. (2009). Social media use in the United States: implications for health communication. J. Med. Internet Res. 11, e48. doi:10.2196/jmir.1249

Cohen, S., Gottlieb, B. H., and Underwood, L. G. (2000). "Social relationships and health," in Social Support Measurement and Intervention: A Guide for Health and Social Scientists (Oxford University Press), 1-25.

Déglise, C., Suggs, L. S., and Odermatt, P. (2012). SMS for disease control in developing countries: a systematic review of mobile health applications. J. Telemed. Telecare 18, 273-281. doi:10.1258/jtt.2012.110810

Deng, J., Hu, J., Wu, W., Dong, B., and Wu, H. (2010). Subjective well-being, social support, and age-related functioning among the very old in China. Int. J. Geriatr. Psychiatry 25, 697-703. doi:10.1002/gps.2410

Dunton, G. F., Liao, Y., Intille, S. S., Spruijt-Metz, D., and Pentz, M. (2011). Investigating children's physical activity and sedentary behavior using ecological momentary assessment with mobile phones. Obesity 19, 1205-1212. doi:10.1038/oby.2010.302

Ellison, N. B., Steinfield, C., and Lampe, C. (2007). The benefits of Facebook "friends": social capital and college students' use of online social network sites. J. Comput. Mediat. Commun. 12, 1143-1168. doi:10.1111/j.1083-6101.2007.00367.x

Fanning, J., Mullen, S. P., and McAuley, E. (2012). Increasing physical activity with mobile devices: a meta-analysis. J. Med. Internet Res. 14, e161. doi:10.2196/ jmir.2171

Finn, J. (1999). An exploration of helping processes in an online self-help group focusing on issues of disability. Health Soc. Work 24, 220-231. doi:10.1093/ hsw/24.3.220

Goldsmith, D. J. (2004). Communicating Social Support. New York, NY: Cambridge.

Goldsmith, D. J., and Albrecht, T. L. (2011). "Social support, social networks, and health," in The Routledge Handbook of Health Communication, eds T. L.Thompson, R.Parrott, and J. F.Nussbaum (New York: Routledge), 335-348.

Hall, J. A., and Baym, N. K. (2012). Calling and texting (too much): mobile maintenance expectations, (over) dependence, entrapment, and friendship satisfaction. New Media Soc. 14, 316-331. doi:10.1177/1461444811415047

Han, J. Y., Kim, J. H., Yoon, H. J., Shim, M., McTavish, F. M., and Gustafson, D. H. (2012). Social and psychological determinants of levels of engagement with an online breast cancer support group: posters, lurkers, and nonusers. J. Health Commun. 17, 356-371. doi:10.1080/10810730.2011.585696 
Head, K. J., Noar, S. M., Iannarino, N. T., and Harrington, N. G. (2013). Efficacy of text messaging-based interventions for health promotion: a meta-analysis. Soc. Sci. Med. 97, 41-48. doi:10.1016/j.socscimed.2013.08.003

Helgeson, V. S., and Gottlieb, B. H. (2000). "Support groups," in Social Support Measurement and Intervention: A Guide for Health and Social Scientist, eds S. Cohen, L.G. Underwood, and B. G. Gottlieb (Oxford: Oxford University Press), 221-245.

Hwang, K. O., Ottenbacher, A. J., Green, A. P., Cannon-Diehl, M. R., Richardson, O., Bernstam, E. V., et al. (2010). Social support in an Internet weight loss community. Int. J. Med. Inform. 79, 5-13. doi:10.1016/j.ijmedinf.2009.10.003

Kanbara, S., Taniguchi, H., Sakaue, M., Wang, D. H., Takaki, J., Yajima, Y., et al. (2008). Social support, self-efficacy and psychological stress responses among outpatients with diabetes in Yogyakarta, Indonesia. Diabetes Res. Clin. Pract. 80, 56-62. doi:10.1016/j.diabres.2007.12.015

Kim, J., and Lee, J. E. (2011). The Facebook paths to happiness: effects of the number of Facebook friends and self-presentation on subjective well-being. Cyberpsychol. Behav. Soc. Netw. 6, 359-364. doi:10.1089/cyber.2010.0374

LeRouge, C., Van Slyke, C., Seale, D., and Wright, K. (2014). Baby boomers' adoption of consumer health technologies: survey on readiness and barriers. J. Med. Internet Res. 16, e200. doi:10.2196/jmir.3049

Liu, C. Y., and Yu, C. P. (2013). Can Facebook induce well-being? Cyberpsychol. Behav. Soc. Netw. 16, 674-678. doi:10.1089/cyber.2012.0301

Luxton, D. D., McCann, R. A., Bush, N. E., Mishkind, M. C., and Reger, G. M. (2011). mHealth for mental health: integrating smartphone technology in behavioral healthcare. Prof. Psychol. Res. Pract. 42, 505-512. doi:10.1037/a0024485

Nabi, R. L., Prestin, A., and So, J. (2013). Facebook friends with (health) benefits? Exploring social network site use and perceptions of social support, stress, and well-being. Cyberpsychol. Behav. Soc. Netw. 16, 721-727. doi:10.1089/ cyber.2012.0521

National Cancer Institute. (2013). Health Information National Trends Survey. Available at: http://hints.cancer.gov

Ncama, B. P., McInerney, P. A., Bhengu, B. R., Corless, I. B., Wantland, D. J., Nicholas, P. K., et al. (2008). Social support and medication adherence in HIV disease in KwaZulu-Natal, South Africa. Int. J. Nurs. Stud. 45, 1757-1763. doi:10.1016/j.ijnurstu.2008.06.006

Oh, H. J., Ozkaya, E., and LaRose, R. (2014). How does online social networking enhance life satisfaction? The relationships among online supportive interaction, affect, perceived social support, sense of community, and life satisfaction. Comput. Human Behav. 30, 69-78. doi:10.1016/j.chb.2013.07.053

Rains, S. A., Peterson, E. B., and Wright, K. B. (2015). Communicating social support in computer-mediated contexts: a meta-analytic review of content analyses examining support messages shared online among individuals coping with illness. Commun. Monogr. 82, 403-430. doi:10.1080/03637751.2015.1019530

Rains, S. A., and Young, V. (2009). A meta-analysis of research on formal computer-mediated support groups: examining group characteristics and health outcomes. Hum. Commun. Res. 35, 309-336. doi:10.1111/j.1468-2958.2009.01353.x

Rao, D., Chen, W. T., Pearson, C. R., Simoni, J. M., Fredriksen-Goldsen, K., Nelson, K., et al. (2012). Social support mediates the relationship between HIV stigma and depression/quality of life among people living with HIV in Beijing, China. Int. J. STD AIDS 23, 481-484. doi:10.1258/ijsa.2009.009428

Revenson, T. A., Schiaffino, K. M., Majerovitz, S. D., and Gibofsky, A. (1991). Social support as a double-edged sword: the relation of positive and problematic support to depression among rheumatoid arthritis patients. Soc. Sci. Med. 33, 807-813. doi:10.1016/0277-9536(91)90385-P

Shaw, L. H., and Gant, L. M. (2002). In defense of the Internet: the relationship between Internet communication and depression, loneliness, self-esteem, and perceived social support. Cyberpsychol. Behav. 5, 157-171. doi:10.1089/109493102753770552

Sivaram, S., Zelaya, C., Srikrishnan, A. K., Latkin, C., Go, V. F., Solomon, S., et al. (2009). Associations between social capital and HIV stigma in Chennai, India: considerations for prevention intervention design. AIDS Educ. Prev. 21, 233-250. doi:10.1521/aeap.2009.21.3.233

Sun, H., Zhang, J., and Fu, X. (2007). Psychological status, coping, and social support of people living with HIV/AIDS in central China. Public Health Nurs. 24, 132-140. doi:10.1111/j.1525-1446.2007.00617.x

Tanis, M. (2008). Health-related online forums: what's the big attraction. J. Health Commun. 13, 698-714. doi:10.1080/10810730802415316
Thoits, P. A. (2011). Mechanisms linking social ties and support to physical and mental health. J. Health Soc. Behav. 52, 145-161. doi:10.1177/0022146510395592

Tong, S. T., Heinmann-LaFave, D., Jeon, J., Kolodziej-Smith, R., and Warshay, N. (2013). The use of pro-ana blogs for online social support. Eat. Disord. 21, 408-422. doi:10.1080/10640266.2013.827538

Turner, J. W., Grube, J. A., and Meyers, J. (2001). Developing an optimal match within online communities: an exploration of CMC support communities and traditional support. J. Commun. 51, 231-251. doi:10.1111/j.1460-2466.2001. tb02879.x

Valente, T. W., and Saba, W. P. (1998). Mass media and interpersonal influence in a reproductive health communication campaign in Bolivia. Commun. Res. 25, 96-124. doi:10.1177/009365098025001004

van Ingen, E., and Wright, K. B. (2016). Predictors of mobilizing online coping versus offline coping resources after negative life events. Comput. Human Behav. 59, 431-439. doi:10.1016/j.chb.2016.02.048

Van Tilburg, T. (1998). Losing and gaining in old age: changes in personal network size and social support in a four-year longitudinal study. J. Gerontol. B Psychol. Sci. Soc. Sci. 53, S313-S323. doi:10.1093/geronb/53B.6.S313

Walther, J. B., and Boyd, S. (2002). "Attraction to computer-mediated social support," in Communication Technology and Society: Audience Adoption and Uses, eds C. A.Lin and D.Atkin (Cresskill, NJ: Hampton Press), 153-188.

Wicks, P., Massagli, M., Frost, J., Brownstein, C., Okun, S., Vaughan, T., et al. (2010) Sharing health data for better outcomes on PatientsLikeMe. J. Med. Internet Res. 12, e19. doi:10.2196/jmir.1549

Wolitski, R. J., Pals, S. L., Kidder, D. P., Courtenay-Quick, C., and Holtgrave, D. R. (2008). The effects of HIV stigma on health, disclosure of HIV status, and risk behavior of homeless and unstably housed persons living with HIV. AIDS Behav. 13, 1222-1232. doi:10.1007/s10461-008-9455-4

Wright, K. (2000a). Computer-mediated social support, older adults, and coping. J. Commun. 50, 100-118. doi:10.1111/j.1460-2466.2000.tb02855.x

Wright, K. (2000b). Perceptions of on-line support providers: an examination of perceived homophily, source credibility, communication and social support within on-line support groups. Commun. Q. 48, 44-59. doi:10.1080/01463370009385579

Wright, K. B. (2015). "Computer-mediated support for health outcomes: psychological influences on support processes," in The Psychology of Communication Technology, ed. S.Sundar (Malden, MA: Wiley-Blackwell), 488-506.

Wright, K. B., Abendschein, B., Wombacher, K., O'Connor, M., Hoffman, M., Dempsey, M., et al. (2014). Work-related communication technology use outside of regular work hours and work life conflict the influence of communication technologies on perceived work life conflict, burnout, job satisfaction, and turnover intentions. Manag. Commun. Q. 28, 507-530. doi:10.1177/0893318914533332

Wright, K. B., and Bell, S. B. (2003). Health-related support groups on the Internet: linking empirical findings to social support and computer-mediated communication theory. J. Health Psychol. 8, 37-52. doi:10.1177/1359105303008001429

Wright, K. B., and Miller, C. H. (2010). A measure of weak tie/strong tie support network preference. Commun. Monogr. 77, 502-520. doi:10.1080/03637751. 2010.502538

Wright, K. B., and Rains, S. A. (2013). Weak-tie support network preference, health-related stigma, and health outcomes in computer-mediated support groups. J. Appl. Commun. Res. 41, 309-324. doi:10.1080/00909882.2013.792435

Conflict of Interest Statement: The author declares that the research was conducted in the absence of any commercial or financial relationships that could be construed as a potential conflict of interest.

The reviewer PC and handling editor declared their shared affiliation, and the handling editor states that the process nevertheless met the standards of a fair and objective review.

Copyright (c) 2016 Wright. This is an open-access article distributed under the terms of the Creative Commons Attribution License (CC BY). The use, distribution or reproduction in other forums is permitted, provided the original author(s) or licensor are credited and that the original publication in this journal is cited, in accordance with accepted academic practice. No use, distribution or reproduction is permitted which does not comply with these terms. 